\title{
Armadillo meat intake was not associated with leprosy in a case control study, Curitiba (Brazil)
}

\author{
Juliano Vilaverde Schmitt ${ }^{1 /}$, Ivone Tod Dechandt ${ }^{1}$, Gisele Dopke ${ }^{1}$, Maria Luiza Ribas ${ }^{1}$, \\ Felipe Bochnia Cerci', Juliana Maria Zucco Viesi', Helena Zenedin Marchioro', \\ Mariana Martins Bardou Zunino', Hélio Amante Miot ${ }^{2}$
}

${ }^{1}$ Fundação Pró-Hansen, Rua Fernando Amaro 1116, 80050-020 Curitiba, PR, Brasil ²Departamento de Dermatologia e Radioterapia, Faculdade de Medicina de Botucatu, Universidade Estadual Paulista, Botucatu, SP, Brasil

Leprosy's progression and its maintained endemic status, despite the availability of effective treatments, are not fully understood and recent studies have highlighted the possibility of involved Mycobacterium leprae ambient reservoirs. Wild armadillos can carry leprosy and, because their meat is eaten by humans, development of the disease among armadillo meat consumers has been investigated. This study evaluated the frequency of armadillo meat intake among leprosy patients as well as age and gender matched controls with other skin diseases from a dermatological unit. Armadillo meat consumption among both groups was adjusted by demographic and socioeconomic covariates based on a conditional multiple logistic regression model. One hundred twenty-one cases and 242 controls were evaluated; they differed in socioeconomic variables such as family income, hometown population and access to treated water. The multivariate analysis did not show an association between the intake of armadillo meat and leprosy (odds ratio = 1.07; CI 95\% 0.56-2.04), even when only cases with no known contacts were analyzed. We conclude that leprosy is not associated with the intake of armadillo meat in these patients.

Key words: leprosy - Hansen's disease - HD - risk - case and control study - armadillos

Although effective treatments have been developed, leprosy remains a serious public health problem in some developing countries. Approximately $90 \%$ of worldwide cases are concentrated in only six countries: India, Brazil, Nepal, Myanmar, Mozambique and Madagascar. Brazil registered about 36,000 new cases in 2009 and was the only country in the Americas that did not attain the prevalence goal of less than one case per 10,000 inhabitants, as proposed by the World Health Organization and accepted by the government in 1991 (Martelli et al. 2002, Moreira et al. 2008, DATASUS 2010).

Leprosy is transmitted primarily by interpersonal contact over a prolonged coexistence with untreated multibacillary patients; the main sources of bacteria are likely mucous membranes of the upper airways. Mycobacterium leprae appears to be highly infectious among humans, but displays low pathogenicity and a long incubation period (Martelli et al. 2002).

The disease dynamics of leprosy depend on individual susceptibility to the illness, bacillary supply and nutritional and sanitary conditions, which may explain why only a percentage of household contacts of an infected subject get sick and why occurrences among health care workers are rare (Sommerfelt et al. 1985).

\footnotetext{
+ Corresponding author: julivs@gmail.com

Received 6 April 2010

Accepted 17 September 2010
}

The role of asymptomatic carriers in the progression and natural history of leprosy is not well quantified. However, in endemic countries, more than half of affected patients report no contact with leprosy patients. Similarly, the occurrence of isolated cases in areas considered free of the disease stimulates the investigation of other means of contagion (Richardus et al. 2005, Lane et al. 2006).

$M$. leprae has previously been identified in water, plants, in the soil of endemic areas and in wild animals such as one armadillo species (Dasypus novemcinctus), which even demonstrates specific skin lesions. A North American study demonstrated the transmission of leprosy among such animals, reporting a prevalence of up to $19 \%$ among armadillos from that region (Matsuoka et al. 1999, Chakrabarty \& Dastidar 2001, Paige et al. 2002, Truman 2005, Deps et al. 2008, Lavania et al. 2008).

Epidemiological studies in the southern United States and in Brazil [state of Espírito Santo (ES)] suggest a higher frequency of meat intake and other types of direct armadillo contact among leprosy patients when compared with a control population. However, such findings have not been confirmed by other researchers (Deps et al. 2003, 2008, Kerr-Pontes et al. 2006, Clark et al. 2008).

In the present study, reports regarding the consumption of armadillo meat among leprosy patients was evaluated and compared with those of patients with other skin conditions who attended the same reference dermatological center in Curitiba, state of Paraná (PR), Brazil.

\section{PATIENTS, MATERIALS AND METHODS}

A matched case-control study was performed involving patients attending the Pró-Hansen Foundation (Curitiba, PR) between 2005-2009. All patients were interviewed in person according to a standardized questionnaire. 
All patients over 15 years of age with a positive diagnosis of leprosy were considered eligible. Controls were selected among patients with other skin diseases and were matched by gender and age in a 2:1 ratio.

Patients with an inconclusive diagnosis of leprosy or patients who could not recall exactly whether they had or had not consumed any armadillo meat were excluded.

The primary independent variable was armadillo meat consumption at anytime in life before the onset of leprosy. Due to memory bias and the diverse of educational levels of the study participants, they were not asked about the armadillo species consumed; however, the D. novemcinctus, or tatu-galinha is popularly recognized as the most appropriate for consumption in the region studied.

Participants were classified according to their hometown and its current population, family income, number of co-inhabitants in the household, previous contact with leprosy patients, consumption of meat from other wild animals, urbanization of the area where they live and access to treated water.

Categorical variables were represented by their frequencies and were bivariately compared with a Chi-square test or Fisher's exact test. Continuous variables were represented by a mean or median and were bivariately compared by Student's $t$ test or a Mann-Whitney test. Later, odds ratios were adjusted for all covariates based on a conditional multiple logistic regression. Two-tailed values of $p<0.05$ were considered significant. When multiple comparisons were performed, significance of the $p$ value was adjusted by Bonferroni's correction. The data were analyzed by the SPSS17.0 software.

The sample size was initially estimated based on data available in the Brazilian scientific literature (Deps et al. 2008) and by adopting a two-tailed alpha significance of 0.01 and power of 0.9 .

TABLE I

Comparison of clinical and demographic variable between the groups

\begin{tabular}{|c|c|c|c|c|c|c|c|}
\hline Variable & Cases & $\%$ & Controls & $\%$ & Odds ratio & CI 95\% & $\mathrm{p}^{b}$ \\
\hline \multicolumn{8}{|l|}{$\operatorname{Sex}^{a}$} \\
\hline Female & 51 & 42 & 102 & 42 & 1 & - & - \\
\hline Male & 70 & 58 & 140 & 58 & 1 & - & - \\
\hline \multicolumn{8}{|l|}{$\mathrm{Age}^{a}$} \\
\hline Average & 48 & - & 49 & - & - & - & - \\
\hline Standard deviation & 15 & - & 15 & - & - & - & - \\
\hline \multicolumn{8}{|l|}{$\begin{array}{l}\text { Hometown } \\
(1,000 \text { inhabitants) }\end{array}$} \\
\hline Median & 26.7 & - & 41.7 & - & - & - & $<0.01$ \\
\hline IQD & 38.2 & - & 1780.8 & - & - & - & - \\
\hline \multicolumn{8}{|l|}{$\begin{array}{l}\text { Residence } \\
\text { (1,000 inhabitants) }\end{array}$} \\
\hline Median & 1797.4 & - & 1797.4 & - & - & - & 0.66 \\
\hline IQD & 1715.4 & - & 1685.4 & - & - & - & \\
\hline Treated water & 109 & 90 & 232 & 96 & 0.39 & $0.16-0.93$ & 0.03 \\
\hline Residence in urban area & 112 & 93 & 219 & 91 & 1.31 & $0.53-2.69$ & 0.56 \\
\hline \multicolumn{8}{|l|}{ Family size } \\
\hline Median & 3 & - & 3 & - & - & - & 0.65 \\
\hline IQD & 2 & - & 2 & - & - & - & - \\
\hline \multicolumn{8}{|l|}{ Family income (minimum wages) } \\
\hline Up to 1 & 41 & 34 & 24 & 10 & 4.66 & $2.65-8.20$ & $<0.01$ \\
\hline $1-5$ & 74 & 61 & 186 & 77 & 0.47 & $0.30-0.76$ & $<0.01$ \\
\hline More than 5 & 6 & 5 & 32 & 13 & 0.34 & $0.14-0.84$ & 0.02 \\
\hline Contact with leprosy patients & 42 & 35 & 16 & 7 & 7.51 & $4.00-14.10$ & $<0.01$ \\
\hline Armadillo meat intake & 81 & 67 & 152 & 63 & 1.20 & $0.77-1.90$ & 0.44 \\
\hline Other wild animals' meat intake & 73 & 60 & 134 & 55 & 1.23 & $0.79-1.91$ & 0.37 \\
\hline \multicolumn{8}{|l|}{ Baciloscopy } \\
\hline Paucibacillary & 38 & 31 & - & - & - & - & - \\
\hline Multibacillary & 83 & 69 & - & - & - & - & - \\
\hline
\end{tabular}

$a$ : matched variables; $b$ : unadjusted $\mathrm{p}$ value; IQD: inter-quartile deviation. Values in bold are statistically significant. 
Ethics - The project was approved by the council board of the Pró-Hansen Foundation (01/2006).

\section{RESULTS}

One hundred twenty-one leprosy patients and 242 controls with other skin diseases were evaluated. Clinical and demographic data are shown in Table I.

The most frequent disorders among controls were: psoriasis $(13 \%)$, acne $(7 \%)$, basal cell carcinoma $(7 \%)$, actinic keratosis $(7 \%)$, onicomycosis $(6 \%)$, melasma (5\%) and vitiligo (5\%).

Discrepancies were observed between cases and controls regarding their hometown population size, family income, contact with leprosy patients and access to treated water (Table I). The intake of armadillo meat did not differ significantly between the groups.

The multivariate analysis also did not identify the consumption of armadillo meat as a risk factor for leprosy (Table II). Armadillo meat intake was not significant even when cases were submitted to a stratified analysis regarding contact with leprosy patients, their bacillary load, gender and age group.

\section{DISCUSSION}

Reported armadillo meat intake was not associated with the development of leprosy in the population we studied. However, the analysis confirmed observations by studies conducted in the North and Northeast Regions of Brazil that found leprosy to be directly associated with socioeconomic indicators and, possibly, to poor sanitary conditions. Mean ages and genders were similar to other Brazilian studies, confirming a representative sample, despite differences in ethnic composition and the heterogeneity of the social and leprosy indices of Brazilian Regions (Sommerfelt et al. 1985, Kerr-Pontes et al. 2004, DATASUS 2010).
PR is located in the South of Brazil and is an area with endemic leprosy, with a detection rate of 1.1 cases per 10,000 inhabitants in 2009. It is populated by armadillos to a great extent, although the prevalence of animals infected with M. leprae has not been mapped in the municipalities studied (Wilson \& Reeder's 2009, DATASUS 2010). However, in ES the prevalence of anti-PGL-1 in wild armadillos is as high as $10.6 \%$ (Deps et al. 2008).

Armadillos are edentous mammals originally from South America that arrived in North America in the last few centuries. Currently, 21 species exist in nature. The origin of leprosy among armadillos is currently not well understood, but evidence suggests a recent human source of contamination because leprosy reached America after being carried by Europeans (Monot et al. 2005). Despite prohibition by environment protection institutions, contact with armadillos and the intake of its meat is relatively frequent in Brazil, according to several reports (Rodrigues et al. 1993, Deps et al. 2008, Hamilton et al. 2008).

Direct armadillo contact seems to be more common among older males in lower socioeconomic conditions and among residents of rural areas. Similarly, leprosy is associated with social inequality, poverty, malnutrition and poor sanitary conditions, which are all superposed characteristics, which must be analyzed together in risk estimation studies (Martelli et al. 2002, Kerr-Pontes et al. 2004, 2006, Silva Sobrinho \& Mathias 2008).

The present investigation asked patients only about previous meat consumption; however, cooking should kill M. leprae and gastrointestinal transmission of leprosy is not supported by epidemiologic studies. Nevertheless, a reasonable proportion of interviewed patients that consumed armadillos had other forms of contact with the animal such as hunting, handling or preparation of the meat as, in the studied region, armadillo meat is not commercially available.

TABLE II

Prevalence of armadillo meat intake adjusted by the remaining covariates ${ }^{a}$

\begin{tabular}{lccc}
\hline Variable & Odds ratio & CI 95\% & $\mathrm{p}$ \\
\hline Armadillo meat intake & 1.07 & $0.56-2.04$ & 0.84 \\
Gender & 1.09 & $0.64-1.85$ & 0.75 \\
Age & 0.99 & $0.97-1.01$ & 0.22 \\
Hometown (10,000 inhabitants) & 0.99 & $0.98-0.99$ & $<\mathbf{0 . 0 1}$ \\
Current residence (10,000 inhabitants) & 1.00 & $0.99-1.00$ & 0.35 \\
Treated water & 0.54 & $0.19-1.55$ & 0.25 \\
Family size & 1.10 & $0.94-1.30$ & 0.24 \\
Family income (minimum wages) & & & \\
$\quad$ Up to 1 & 7.03 & $2.27-21.76$ & $<\mathbf{0 . 0 1}$ \\
1-5 & 1.63 & $0.61-4.38$ & 0.34 \\
$\quad$ More than 5 & 1.00 & - & - \\
Contact with leprosy patients & 8.33 & $4.05-17.14$ & $<\mathbf{0 . 0 1}$ \\
Wild animal meat intake & 1.49 & $0.82-2.70$ & 0.19 \\
Constant & - & - & 0.38 \\
\hline
\end{tabular}

$a: \mathrm{p}$ (complete model $)<0.01$. 
Deps et al. (2008) investigated 1,100 patients and verified that $83 \%$ of individuals with direct armadillo contact ate the meat. Furthermore, they disclosed no significant difference in the risk of leprosy associated with different types of contact, such as eating vs. handling (Deps et al. 2008). Thus, meat consumption may serve as a proxy for some other form of direct armadillo contact.

Epidemiological studies concerning armadillo contact and leprosy are very heterogeneous regarding the methodology and the population profiles, preventing the compilation of study results (Table III). Moreover, a multivariate approach with an adjustment for prevalence according to previous leprosy contact or socioeconomic variables is of great importance.

The finding that our cases came from towns that were smaller than those of the controls, but did not differ in the sizes of the cities in which they currently reside, may be the result of a migratory phenomenon to larger cities where poor people go in search of jobs (Kerr-Pontes et al. 2004). In the last few decades, there has been an increasing population in urban areas with people coming from rural areas. The former generally have more structured health systems with a larger access to specialized services, which could lead to the diagnosis of a condition that may usually be neglected in small towns with a poorer public health system. However, the analysis of hometown size of indeterminate cases - of a probable earlier diagnosis - and of the multibacillary cases, did not demonstrate a significant difference. Another possibility that could justify this observation is that people who recently egressed from small towns are more exposed to metropolitan areas with scarce sanitary resources, but this aspect was not investigated in our study.

Deps et al. (2008) performed a non-matched controlled study with carriers of chronic diseases in the ES and observed an association between the direct contact (eating or handling) of armadillos and leprosy. The exposure rate to armadillos was similar among patients who reported previous contact with leprosy patients and those without any contact, but there was no multivariate adjustment for this similarity, nor was there any adjustment for socioeconomic variables (Deps et al. 2008).

TABLE III

Prevalences of armadillo meat intake and leprosy published in the literature

\begin{tabular}{|c|c|c|c|}
\hline Reference & $\begin{array}{l}\text { Leprosy } \\
\mathrm{n}(\%)\end{array}$ & $\begin{array}{l}\text { Controls } \\
\mathrm{n}(\%)\end{array}$ & Comments \\
\hline Rodrigues et al. (1993) & $127(62)$ & - & $\begin{array}{l}\text { Non-controlled descriptive study; } 205 \text { patients from state of São } \\
\text { Paulo, Brazil. }\end{array}$ \\
\hline $\begin{array}{l}\text { Bruce et al. (2000) } \\
\text { (Group 1) }\end{array}$ & $36(52)$ & - & $\begin{array}{l}\text { Non-controlled descriptive study; } 69 \text { North-American patients liv- } \\
\text { ing in Texas, USA. }\end{array}$ \\
\hline $\begin{array}{l}\text { Bruce et al. (2000) } \\
\text { (Group 2) }\end{array}$ & $0(-)$ & - & $\begin{array}{l}\text { Non-controlled descriptive study; } 32 \text { patients of Oriental origin living } \\
\text { in Texas, USA. }\end{array}$ \\
\hline Kerr-Pontes et al. (2006) & $141(63)$ & $504(60)$ & $\begin{array}{l}\text { Matched study; } 1,083 \text { patients who did not report previous contact } \\
\text { with leprosy patients. Carried out at state of Ceará, Brazil. }\end{array}$ \\
\hline Deps et al. (2008) & $346(68)$ & $285(48)$ & $\begin{array}{l}\text { Non-matched study; } 1,100 \text { patients from Espírito Santo (ES), Brazil. } \\
\text { Not adjusted for socioeconomic indicators nor for previous contact } \\
\text { to leprosy. }\end{array}$ \\
\hline Deps et al. (2003) & $123(90)$ & $26(15)$ & $\begin{array}{l}\text { Non-matched study; } 309 \text { patients from ES. Not adjusted for socio- } \\
\text { economic indicators nor for previous contact to leprosy. }\end{array}$ \\
\hline Clark et al. (2008) & $13(46)$ & $9(15)$ & $\begin{array}{l}\text { Non-matched study; } 87 \text { patients from Texas, USA. Not adjusted for } \\
\text { socioeconomic indicators. }\end{array}$ \\
\hline Filice et al. (1977) & $1(5)$ & $0(-)$ & $\begin{array}{l}\text { Matched study; } 38 \text { patients and neighbors from Louisiana, USA, no } \\
\text { reports of contacts with leprosy patients. }\end{array}$ \\
\hline Thomas et al. (1987) & $54(61)$ & $25(31)$ & $\begin{array}{l}\text { Non-matched study; } 169 \text { native Mexicans living in Los Angeles, } \\
\text { USA. Not adjusted for socioeconomic indicators. }\end{array}$ \\
\hline Present study & $81(67)$ & $152(63)$ & $\begin{array}{l}\text { Matched study; } 363 \text { dermatological patients from state of Paraná, } \\
\text { Brazil. Performed stratified and multivariate analysis. }\end{array}$ \\
\hline
\end{tabular}


A smaller inquiry was also performed in ES, which showed that about $90 \%$ of patients, most living in a community of leprosy patients, reported the intake of armadillo meat, regardless of their contact with other leprosy patients (Deps et al. 2003).

A study performed in Texas, USA, with tuberculosis patients demonstrated that armadillo meat intake, the handling of rabbits and living in Mexico were independent risk factors for leprosy (Clark et al. 2008).

Another matched study, carried out in Louisiana, USA, and involving patients who did not report any contact with leprosy patients, showed no evidence of an association between consumption, handling or contact with armadillos and leprosy (Filice et al. 1977).

In a subsequent non-matched study in Texas, $52 \%$ of patients were identified as reporting a direct contact with armadillos among USA native leprosy patients, but no patients of Asian origin living in the same area reported any contact with those animals. These elements strengthen the hypothesis that, as in the Brazilian population, contact with armadillos is a culturally common element among Texans (Bruce et al. 2000).

Thomas et al. (1987) performed a case-control study in Los Angeles, USA, that included 89 leprosy patients undergoing treatment who had come from Mexico and compared them with another 80 patients of Mexican origin, cared for in the same clinic, who did not have leprosy, matched by sex, age and area of residence. The authors declared that there were many differences between the groups. However, they only conducted a stratified analysis by gender. In addition, they did not evaluate whether the patients reported having any previous contact with leprosy patients. Forty-six percent of leprosy patients had direct contact with armadillos vs. $19 \%$ of controls and this was considered a significant risk factor when adjusted by the study's variables (Thomas et al. 1987).

Although wild armadillos can carry M. leprae, we do not know either the real proportion of infected wild animals or the regions of the country in which they reside. There are many cases of leprosy of unknown origin in various countries, climates and topographies on the planet, even in regions that are considered free of the disease. Our study confirms this observation because $65 \%$ of all cases did not present any acknowledged contacts (de Wit et al. 1993, Fine et al. 1997, Richardus et al. 2005, Deps et al. 2008).

It is worth pointing out that this situation can also be observed in the Old Continent, where there are no wild armadillos. In Bangladesh, up to $75 \%$ of patients do not report contact with leprosy patients and, in Malawi, southern Africa, this was true for $85 \%$ of all cases. Perhaps the presence of bacillus in the environment or in asymptomatic carriers may help to explain such cases (de Wit et al. 1993, Fine et al. 1997, Matsuoka et al. 1999, Richardus et al. 2005, Lavania et al. 2008).

A study conducted in an endemic area reported the DNA of M. leprae in the nasal swabs of $12 \%$ of the noncontact general population. Another Brazilian study indicated that swimming in rivers, streams and lakes constitute independent factors for the transmission of leprosy among patients who did not report contact with leprosy patients. Moreover, a survey identified viable bacillus organisms in the soil of endemic regions. Such elements demonstrate the need to investigate the indirect modes of transmission of leprosy beyond considering it a zoonosis (de Wit et al. 1993, Matsuoka et al. 1999, Kerr-Pontes et al. 2006, Lavania et al. 2008).

This study has limitations related to the lack of quantitative measurement of the previous intake of armadillo and wild animal meat and the fact that no temporal relationship was established between those events and the diagnosis of leprosy. However, as a retrospective study about an infectious disease with a long incubation time, precision about chronology as a true dose/effect may be difficult to interpret. On the other hand, memory bias should have minimally impacted the final result, provided that one expects that its effect would strengthen the association between armadillo meat intake and leprosy because the contagious feature of leprosy is known in the studied region.

The lack of an association between armadillo meat intake and leprosy may also reflect the non-existence of infected animals in the region of Curitiba instead of the impossibility of zoonotic contamination. An investigation of the prevalence of infected animals in this area may bring further evidence to discuss these hypotheses.

The data suggest that poverty and, possibly, poor sanitation, nutrition and health care conditions construct a favorable environment for acquisition of this illness, its clinical manifestation or a more frequent expression of its symptoms.

Failure to eliminate leprosy the maintenance of high incidence and the associated uncertainty about its natural history and transmission, must motivate the development of clinical surveys and molecular research on this topic (Lockwood \& Suneetha 2005).

In conclusion, there is no evidence to support an association between leprosy and the consumption of armadillo meat in dermatological patients from Curitiba, but rather, evidence supports an association with unfavorable socioeconomic indicators. It is necessary to investigate such occurrences in other regions of Brazil based on controlled studies with large samples and results adjusted to socioeconomic risk factors. Studies should carefully consider any previous contact with leprosy patients, as well as investigate the prevalence of leprosy infections among armadillos in those areas.

\section{REFERENCES}

Bruce S, Schroeder TL, Ellner K, Rubin H, Williams T, Wolf JE Jr 2000. Armadillo exposure and Hansen's disease: an epidemiologic survey in southern Texas. J Am Acad Dermatol 43: 223-228.

Chakrabarty AN, Dastidar SG 2001. Is soil an alternative source of leprosy infection? Acta Leprol 12: 79-84.

Clark BM, Murray CK, Horvath LL, Deye GA, Rasnake MS, Longfield RN 2008. Case-control study of armadillo contact and Hansen's disease. Am J Trop Med Hyg 78: 962-967.

DATASUS - Departamento de Informática do Sistema Único de Saúde/Ministério da Saúde 2010. [homepage on the Internet]. Epidemiológicas e morbidade. [updated $2010 \mathrm{Feb} 13$; cited 2010 Apr 06]. [about 4 screens]. Available from: dtr2004.saude.gov.br/ sinanweb/tabnet/dh?sinannet/hanseniase/bases/Hansbrnet.def. 
de Wit MY, Douglas JT, McFadden J, Klatser PR 1993. Polymerase chain reaction for detection of Mycobacterium leprae in nasal swab specimens. J Clin Microbiol 31: 502-506.

Deps PD, Alves BL, Gripp CG, Aragao RL, Guedes B, Filho JB, Andreatta MK, Marcari RS, Prates I, Rodrigues LC 2008. Contact with armadillos increases the risk of leprosy in Brazil: a case control study. Indian J Dermatol Venereol Leprol 74: 338-342.

Deps PD, Faria LV, Gonçalves VC, Silva DA, Ventura CG, Zandonade EL 2003. Aspectos epidemiológicos da transmissão da hanseníase em relação à exposição ao tatu. Hansen Int 28: 138-144.

Filice GA, Greenberg RN, Fraser DW 1977. Lack of observed association between armadillo contact and leprosy in humans. Am J Trop Med Hyg 26: 137-139.

Fine PE, Sterne JA, Pönnighaus JM, Bliss L, Saui J, Chihana A, Munthali M, Warndorff DK 1997. Household and dwelling contact as risk factors for leprosy in northern Malawi. Am J Epidemiol 146: 91-102.

Hamilton HK, Levis WR, Martiniuk F, Cabrera A, Wolf J 2008. The role of the armadillo and sooty mangabey monkey in human leprosy. Int J Dermatol 47: 545-550.

Kerr-Pontes LR, Barreto ML, Evangelista CM, Rodrigues LC, Heukelbach J, Feldmeier H 2006. Socioeconomic, environmental, and behavioural risk factors for leprosy in North-east Brazil: results of a case-control study. Int J Epidemiol 35: 994-1000.

Kerr-Pontes LR, Montenegro AC, Barreto ML, Werneck GL, Feldmeier H 2004. Inequality and leprosy in Northeast Brazil: an ecological study. Int J Epidemiol 33: 262-269.

Lane JE, Walsh DS, Meyers WM, Klassen-Fischer MK, Kent DE, Cohen DJ 2006. Borderline tuberculoid leprosy in a woman from the state of Georgia with armadillo exposure. J Am Acad Dermatol 55: 714-716.

Lavania M, Katoch K, Katoch VM, Gupta AK, Chauhan DS, Sharma R, Gandhi R, Chauhan V, Bansal G, Sachan P, Sachan S, Yadav VS, Jadhav R 2008. Detection of viable Mycobacterium leprae in soil samples: insights into possible sources of transmission of leprosy. Infect Genet Evol 8: 627-631.

Lockwood DN, Suneetha S 2005. Leprosy: too complex a disease for a simple elimination paradigm. Bull World Health Organ 83: $230-235$.
Martelli CMT, Stefani MMA, Penna GO, Andrade ALSS 2002. Endemias e epidemias brasileiras, desafios e perspectivas de investigação científica: hanseníase. Rev Bras Epidemiol 5: 273-285.

Matsuoka M, Izumi S, Budiawan T, Nakata N, Saeki K 1999. Mycobacterium leprae DNA in daily using water as a possible source of leprosy infection. Indian J Lepr 71: 61-67.

Monot M, Honoré N, Garnier T, Araoz R, Coppée JY, Lacroix C, Sow S, Spencer JS, Truman RW, Williams DL, Gelber R, Virmond M, Flageul B, Cho SN, Ji B, Paniz-Mondolfi A, Convit J, Young S, Fine PE, Rasolofo V, Brennan PJ, Cole ST 2005. On the origin of leprosy. Science 308: 1040-1042.

Moreira MV, Waldman EA, Martins CL 2008. Hanseníase no estado do Espírito Santo, Brasil: uma endemia em ascensão? Cad Saude Publica 24: 1619-1630.

Paige CF, Scholl DT, Truman RW 2002. Prevalence and incidence density of Mycobacterium leprae and Trypanosoma cruzi infections within a population of wild nine-banded armadillos. Am J Trop Med Hyg 67: 528-532.

Richardus JH, Meima A, van Marrewijk CJ, Croft RP, Smith TC 2005. Close contacts with leprosy in newly diagnosed leprosy patients in a high and low endemic area: comparison between Bangladesh and Thailand. Int J Lepr Other Mycobact Dis 73: 249-257.

Rodrigues S, Becaro E, Koizumi F, Alchorne MMA 1993. Tatu e hanseníase. An Bras Dermatol 68: 340-345.

Silva Sobrinho RA, Mathias TAF 2008. Perspectivas de eliminação da hanseníase como problema de saúde pública no estado do Paraná, Brasil. Cad Saude Publica 24: 303-314.

Sommerfelt H, Irgens LM, Christian M 1985. Geographical variations in the occurrence of leprosy: possible roles played by nutrition and some other environmental factors. Int J Lepr Other Mycobact Dis 53: 524-532.

Thomas DA, Mines JS, Thomas DC, Mack TM, Rea TH 1987. Armadillo exposure among Mexican-born patients with lepromatous leprosy. J Infect Dis 156: 990-992.

Truman R 2005. Leprosy in wild armadillos. Lepr Rev 76: 198-208.

Wilson \& Reeder's - Mammal species of the world 2009. [homepage on the Internet]. [updated 2005 Jan 02; cited 2010 Apr 06]. Browse: novemcinctus; [about 2 screens]. Available from: bucknell.edu/MSW3/browse.asp?id=11700009. 